\title{
RANCANG BANGUN WALL CLIMBING
}

\author{
Budiawan Sulaeman ${ }^{1}$ \\ ${ }^{1}$ Dosen FT Universitas Andi Djemma Palopo \\ ${ }^{1}$ budiawan.sulaeman@gmail.com
}

\begin{abstract}
Abstrak
Penelitian ini membahas tentang rancang bangun wall climbing, sebagai salah satu kegiatan positif yang dapat dilakukan oleh pemuda masa kini dalam rangka pembinaan pada generasi muda dalam hal pengembangan sikap, kedisiplinan, maupun melahirkan prestasi dalam olah raga panjat tebing. Wall climbing akan dibangun dengan ketinggian 14,5 meter. Dalam perancangan konstruksinya memperhatikan syarat-syarat keseimbangan pada perhitungan konstruksi rangka batang. Diperhatikan juga mengenai teknik dan perhitungan sambungan yang digunakan, yaitu menggunakan sambungan las dan sambungan baut. Kerangka penyelesaiannya menjelaskan gambar teknik yang digunakan, persiapan bahan, prosedur kerja, teknik pengelasan dan perakitan/assembling.
\end{abstract}

Kata kunci : Wall Climbing, Sambungan, Pengelasan, Perakitan

\section{PENDAHULUAN}

Upaya pemerataan pembangunan di seluruh tanah air, pembangunan daerah yang kurang berkembang seperti kawasan Indonesia timur maka perlu diadakan pembinaan pada remaja sebagai generasi muda yang diharapkan sebagai pengembang sikap dan kedisiplinan dalam masyarakat berbangsa dan bernegara sedini mungkin. Dengan menyadari pemuda sebagai tulang punggung suatu Negara yang nantinya akan menjadi penerus tonggak pemimpin masa depan, karena itu sebagai pemuda kita harus mengasah kemampuan, minat dan bakat kita untuk menciptakan pemuda yang memiliki kepercayaan diri dan dapat menonjolkan kriatifitas yang bersifat positif, salah satu bentuk kegiatan yang dapat dilakukan adalah olah raga panjat tebing.

Seiring dengan perkembangan olah raga tersebut serta untuk menghemat waktu dan prasarana maka dibuatlah suatu bidang yang menyerupai tebing, prasana ini biasa dinamakan papan panjat (Wall Climbing). Penelitian ini membahas tentang rancang bangun wall climbing dengan ketinggian 14,5 meter. Dengan adanya papan panjat tersebut, penulis berharap semoga dunia panjat tebing akan semakin berkembang serta dapat melahirkan atlet-atlet yang handal yang mampu berprestasi di tingakat nasional maupun internasional.

Papan Panjat (Wall Climbing) adalah sarana olah raga tebing buatan yang terdiri dari rangka baja. Dimana rangka tersebut terdiri dari besi siku yang dihubungkan dengan sambungan baut dan sambungan las yang diikat dengan plat simpul sehingga berbentuk seperti menara yang pada salah satu sisinya dipasangi beberapa multipleks yang di bentuk sedemikian rupa sehingga menyerupai sebuah tebing. Wall Climbing ini merupakan suatu rangka batang sehingga dalam perencanaan alat ini kami mengacu pada konstruksi rangka batang denggan menggunakan syarat-syarat keseimbangan.

Suatu benda yang di bebani oleh suatu kumpulan gaya menjadi seimbang jika resultantenya menjadi nol dan tidak berada dalam ketidakterbatasan. Dalam "bahasa statistika" kita mengatakan.

$$
\sum F X=0, \sum F Y=0, \sum M=0
$$

Penentuan $\sum F x=0$ dan $\sum F Y=0$ menjadi keseimbangan absis dan ordinat dari kumpulan gaya. Penentuan $\sum M=0$ menjadi keseimbangan momen terhadap titik 
kutub $D$ sembarang. Supaya suatu benda menjadi seimbang ketika syarat keseimbangan tersebaut diatas harus menjadi nol. Ketika syarat keseimbangan tersebut diatas dapat juga dapat digantikan oleh tiga syarat keseimbangan momen. Harus diperhatikan, bahwa titik kutub $A . B$

$$
\sum M A=0, \sum M B=0, \sum M C=0
$$

Dan $\mathrm{C}$ tidak boleh dalam/ pada suatu garis lurus. Penentuan $\sum M A=0$ menentukan bahwa resultan $R=O$ atau $\mathrm{R}$ menembus pada titik kutub $A$. Penentuan $\sum M A=0$, dan $\sum M B=0$ menetapkan bahwa resultan $R=0$ atau $R$ melalui titik kutub $A$ dan $B$. Penentuan $\sum M A=0$ dan $\sum M C=0$ menetapkan, bahwa; jika resultante $R$ melalui titik kutub $A$ dan $B$, momen $R$ terhadap titk kutub $C$ harus menjadi nol. Akan tetapi oleh karena jarak garis $A-B$ terhadap titik kutub $C$ tidak menjadi nol, resultan $R$ harus menjadi nol. Kedua syarat keseimbangan (1) dan (2) bisa digabung seperti dibawa ini :

$$
\sum X=0, \sum M A=0, \sum M B=0
$$

Jika dua titik kutup A dan B tidak berada pada suatu garis lurus yang sukusuku pada absis x (atau sejajar dengan ordinat y), dengan cara garis kita dapat menentukan syarat-syarat keseimbangan. Jika poligon batang tarik pada gambar situasi dan gambar gaya menjadi tertutup kumpulan gaya itu menjadi berimbang. Ketentuan ini dibuktikan dengan gambar berikut:

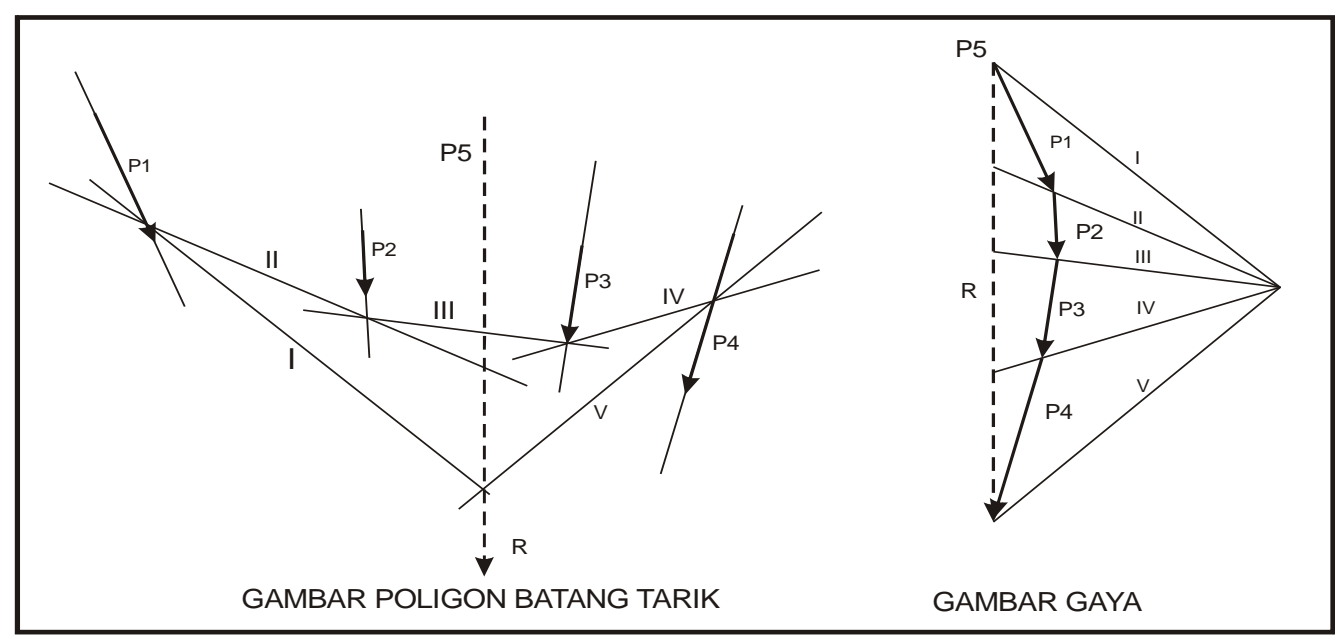

Gambar 1. Poligon batang tarik dan gaya

Jika pada gambar ini gaya P5 sama dengan $\mathrm{R}$ tetapi dengan jurusan berlawanan, poligon batang tarik pada gambar gaya menjadi tertutup dan $\sum X=0$ dan $\sum Y=0$, maka garis kerja $\mathrm{P} 5$ dan $\mathrm{R}$ dan sama poligan batang tarik pada gambar situasi menjadi tertutup juga oleh karena gaya pertolongan I dan $\mathrm{V}$ mempunyai titik tangkap pada garis kerja P5 dan $\sum M=0$. Tetapi jika misalnya P5 berada pada tempat P5' gaya pertolongan I dan V tidak mempunyai titik tangkap pada garis kerja P5" dan keseimbangan momen tidak menenggapi. Syarat keseimbangan pada statika yang terpakai peda pembangunan biasanya timbul ketentuan, bahwa suatu kumpulan gaya $\mathrm{P}$ resultante $\mathrm{R}$ di hapuskan oleh kumpulan gaya $\mathrm{P}$ atau $\mathrm{R}$ yang seimbang dengan resultante $\mathrm{R}$. 
a) Perhitungan reaksi pada tumpuan

Pada tumpuan suatu konstruksi rangka batang timbul gaya atau reaksi tumpuan yang diakibatkan oleh pembebanan pada konstruksi itu, reaksi tumpuan harus seimbang dengan beban konstruksi.

b) Gaya dalam

Pada keseimbangan harus diperhatikan bahwa konstruksi rangka batang seluruhnya harus seimbang.

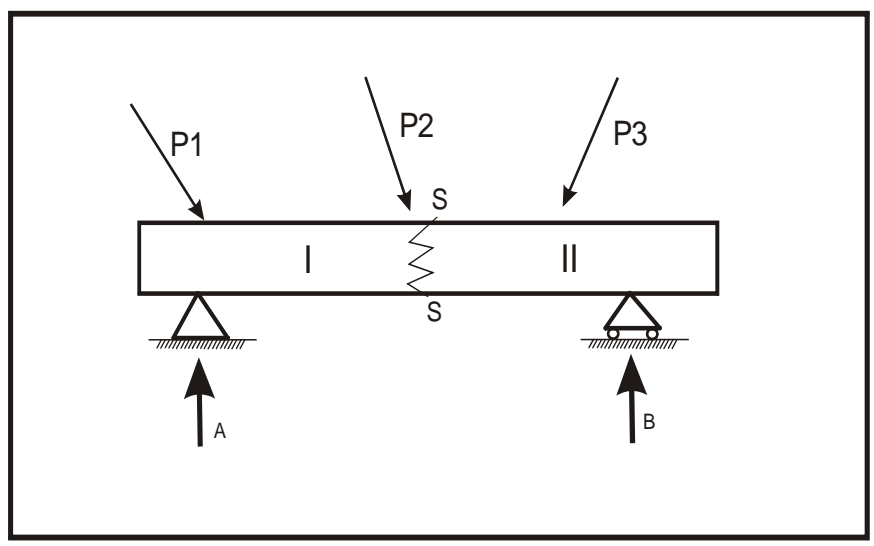

Gambar 2. Gaya A dan B

Ketika memotong benda, yang dibebani oleh gaya $P 1-P 3$ dan yang bertumpu pada tumpuan A dan B dalam keseimbangan, menurut garis s-s kedalam bagian I dan bagian II.

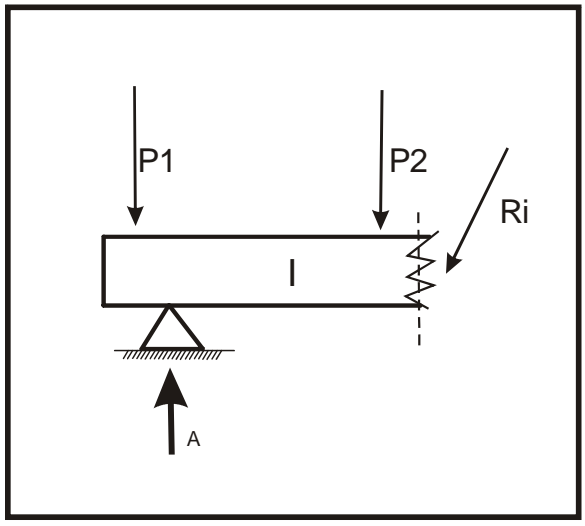

Gambar 3. Gaya A

Pada umumnya reaksi $R i$ ditentukan pada titik pada berat potongan $s-s$ yang sembarang. Ukuran-ukuran atau nilai $R i$ ditentukan secara statis dan dikatakan:

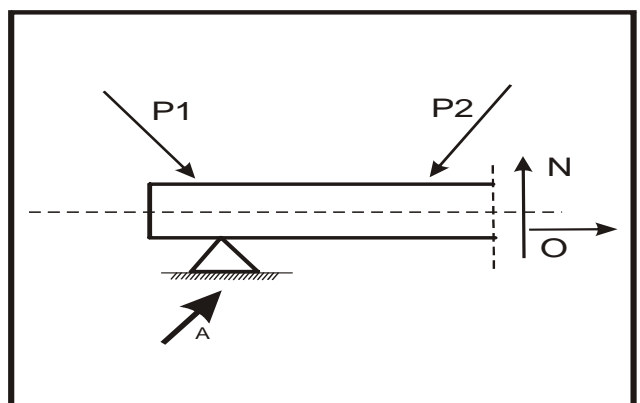

Gambar 4. Gaya A' 
Kita membebani suatu bidang $F$ dengan suatu beban merata $q=1$ (misalnya bidang itu terdiri dari satu pelat dari bahan bangunan seragam). Kemudian kita bagi bidang $F$ atas sembarang jumlah bidang kecil $f$ i hasil atau ukuran bidang kecil $f$ i ini merupakan suatu gaya oleh beban merata. Titik berat $S$ kita ketahui sebagai titik tangkap resultante gaya $f i$ dalam arah horizontal dan vertical. Atas dasar ketentuan bahwa resultante menjadi sama dengan jumlah momen gaya masing - masing maka dapat kita tentukan:

$$
X s . \sum f i=\sum X i . f i \quad \text { dan } \quad Y s . \sum f i=\sum Y i . f i
$$

Dengan menggunakan rumus ini kita bisa menentukan jarak titik berat $Y s$ dan $X s$ sebagai berikut:

$$
Y s=\frac{\sum Y i \cdot f i}{\sum f i} \quad \text { dan } \quad \mathrm{Xs}=\frac{\sum X i . f i}{\sum f i}
$$

Penyelesaian boleh dilakukan secara grafis atau analitis.

a) Titik berat bidang dengan bentuk sembarang

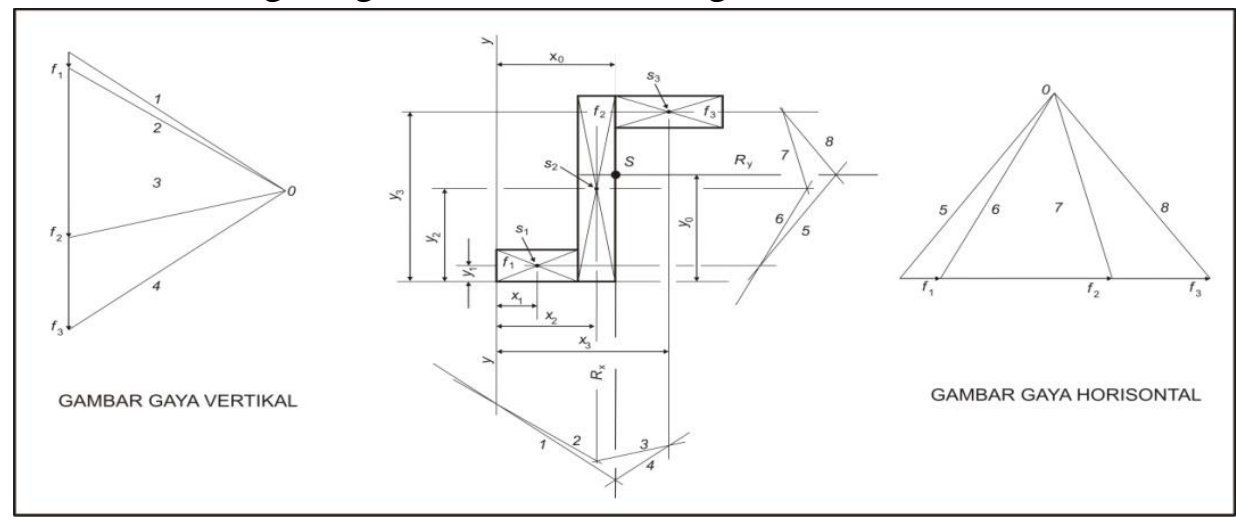

Gambar 5. Gaya vertikal dan horizontal

Gambar situasi: (1) pembagian bidang $F$ kedalam bidang-bidang kecil $f$ dengan titik beratnya sudah kita ketahui; (2) penentuan resultante $R$ dari bidangbidang kecil $f$ dari arah horizontal $(R x)$ dan vertical $(R y)$; (3) penentuan titik berat $S$ pada titiik tangkap $R \mathrm{x}$ dan $R y$. Penyelesaian secara analitis: (1) kita memilih suatu system koordinat $\mathrm{x}-\mathrm{x}$ dan $\mathrm{y}-\mathrm{y}$; (2) penyelesaian dengan penggunaan rumus (C.1)

$$
\begin{gathered}
X s=\frac{\sum(X . f)}{F}=\frac{X 1 \cdot f 1+X 2 . f 2+X 3 \cdot f 3+\cdots \cdot .}{F} \\
Y s=\frac{\sum(X . f)}{F}=\frac{Y 1 \cdot f 1+Y 2 \cdot f 2+Y 3 \cdot f 3+\cdots \cdot .}{F}
\end{gathered}
$$

b) Segitita

Titik berat $S$ berada pada titik potong ketiga garis berat dari sudut pertengahan sisi berhadapan.

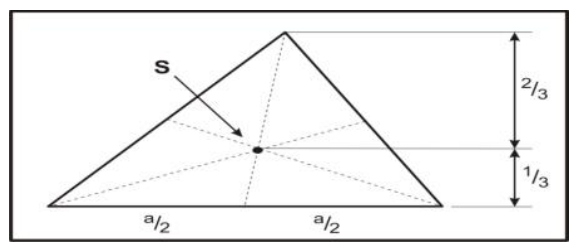

Gambar 6. Segitiga 
c) Trapesium

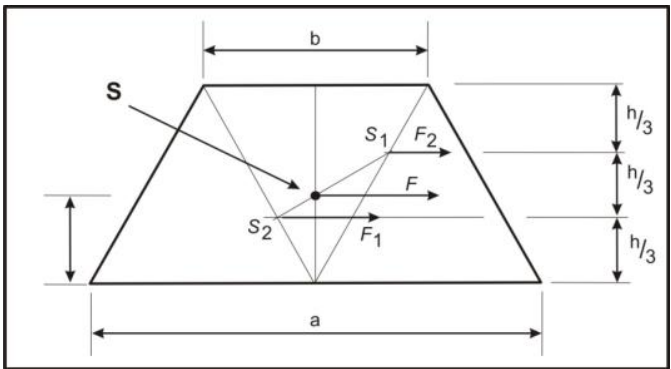

Gambar 7. Trapesium

Secara analisis: titik berat $S$ berada pada garis dari pertengahan dua sisi yang sejajar. Untuk menentukan sejajar $Y_{S}$ kita membagi trapezium atas dua segitiga $F 2$ dan $F 2$. Titik berat pada segitiga itu bisa kita tentukan dengan $S 1$ dan $S 2$ menurut rumus (C.1) kita dapat kita tentukan kemudian:

Secara grafis:

$$
Y_{S}=\frac{\frac{a \cdot h}{2} \cdot \frac{h}{3}+\frac{b \cdot h}{2} \cdot \frac{2 \cdot h}{3}}{\frac{a \cdot h}{2}+\frac{b \cdot h}{2}} \rightarrow Y_{S}=\frac{h}{3} \cdot \frac{a+2 b}{a+b}
$$

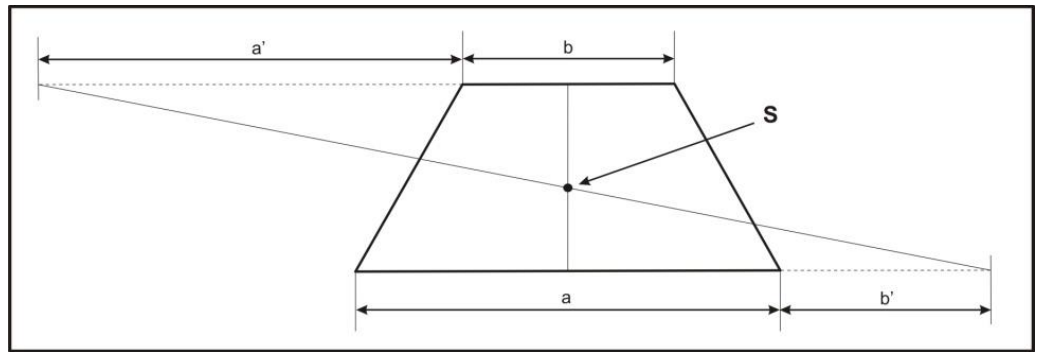

Gambar 8. Trapesium grafis I

Atau,

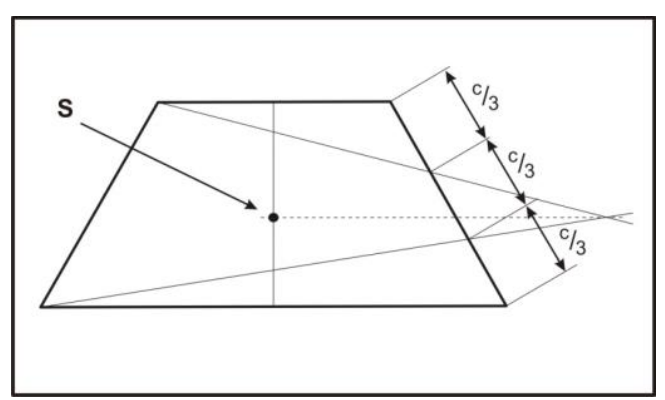

Gambar 9. Trapesium grafis II

d) Segi empat sembarang

Kita membagi segiempat ini dua kali atas dua segitiga dan memdapat dua kali dua titik berat $S 1-S 4$. Kita menyambung sekarang ttitik berat $S 1$ dengan $S 2$ dan $S 3$ dengan $S 4$ pada titik dua garis ini kita dapatkan titik berat $S$.

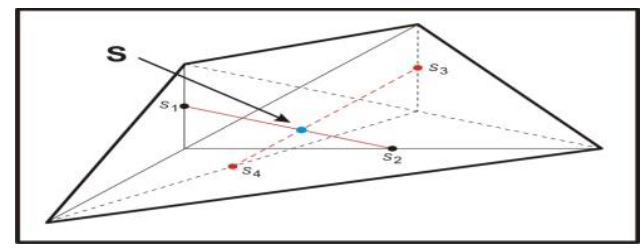

Gambar 10. Segi empat sembarang 
Sambungan adalah pertemuan antara dua atau beberapa buah benda/balok yang saling mengikat antara satu sama lainnya, membentuk satu kesatuan yang kuat. Ikatan pada sambungan tidak menentukan ukuran pada penampang-penampang panjang tetapi juga deformasi dari sambungan tarik. Semakin kecil bidang elemen kontak sambungan. Deformasi semakin besar. Adapun sambungan-sambungan yang digunakan dalam rerancangan ini adalah sambungan las dan baut.

Sambungan las termasuk sambungan tetap yang kuat dan juga rapat. Kekuatan las sangat tergantung pada pekerjanya, bahan elektroda las beserta sambungan las yang dikerjakan. Dalam prakteknya sambungan las banyak digunakan sebagai alat sambung baja karena sambungan las banyak keuntungannya dilihat dari segi estetik maupun ekonomis. Hanya bahan ST 37 dan ST 52 boleh disambung dengan las dan tebalnya terbatas yaitu $25 \mathrm{~mm}$ pada ST 52 dan $30 \mathrm{~mm}$ pada baja ST 37. Macam-macam jenis las: (1) las temu (butt Joint); (2) las T (T Joint); (3) las Sudut (Fillet Joint) dan; (4) las tumpang (Jap Joint).

Sambungan baut termasuk sumbangan tidak tetap, yaitu sambungan yang dapat dibuka kembali tampa merusak buat dan rangkaiannya sambungan buat dapat dipasang dan dilepaskan kembali, sehinga dapat dipastikan selalu terdapat dalam konstruksi mesin. Penggolongan baut menurut bentuk kepalanya adalah segi enam dan segi empat. Menurut fungsinya baut dan mur dapat dibebankan sebagai berikut: (1) baut penjepit; (2) sekrup pengetap; (3) baut khusus; (4) sekrup penetap; (5) sikrup mesin; (6) mur. Plat simpul dipakai untuk mengikat batang - batang dari konstruksi rangka. Jadi fungsi dari plat simpul adalah sebagai stabilisator dari batang - batang yang bertemu pada titik simpul.

Adapun cara mendapatkan titik berat dari Wall Climbing adalah dengan menggunakan persamaan sebagai berikut:

Titik berat $x \quad=\quad$ Jumlah titik berat batang $\mathrm{x} /$ jumlah batang $\mathrm{x}$

$=145,835 / 45$

$=\quad 3,17 \mathrm{~m}$

Titik berat $\mathrm{y} \quad=\quad$ Jumlah titik berat batang $\mathrm{y} / \mathrm{jumlah}$ batang $\mathrm{y}$

$$
\begin{aligned}
& =\quad 376,956 / 45 \\
& =\quad 8,195 \mathrm{~m}
\end{aligned}
$$

Jadi, titik berat Wall Climbing adalah $(3,17: 8,195)$.

Pada perancangan ini, landasan yang digunakan dari bahan UNV 8 dengan panjang 6 meter. Dari perhitungan diperoleh bahwa $\Sigma \mathrm{f}_{\mathrm{x}}$ dan $\Sigma \mathrm{M}$ tidak sama dengan nol, sehingga konstruksi kurang seimbang. Ini berarti landasan yang digunakan kurang memenuhi syarat. Agar landasan tersebut memenuhi syarat keseimbangan maka panjang landasan harus ditambah atau ukurannya diperbesar. Kalau tidak kedua-duanya maka kita dapat menggunakan tali sling baja ataupun pondasi.

Perhitungan baut untuk rangaka dimulai dari rangakateratas yang menahan beban teringan sampai dengan rangka bawa yang menahan beban tebesar ditetapkan: (1) kekuatan titik baut untuk M14 $\left({ }_{\mathrm{B}}^{\delta_{\mathrm{B}}}\right)=140 \mathrm{~kg} / \mathrm{mm}^{2}$; (2) kekuatan tarik baut untuk $\operatorname{M10}\left({ }_{\mathrm{B}}^{\delta_{\mathrm{B}}}\right)=100 \mathrm{~kg} / \mathrm{mm}^{2}$; (3) kekuatan tarik baut untuk M6 $\left({ }_{\mathrm{B}}\right)=60 \mathrm{~kg} / \mathrm{mm}^{2}$; (4) faktor keamanan (v), dipilih 5 untuk beban statis. Tegangan geser yang diizinkan pada buat untuk rangka $=14 \mathrm{~kg} / \mathrm{mm}^{2}$. Tegangan geser yang diizinkan pada baut untuk multipleks $=10 \mathrm{~kg} / \mathrm{mm}^{2}$. Tegangan geser yang diizinkan pada baut untuk point $=6 \mathrm{~kg} / \mathrm{mm}^{2}$.

Perhitungan baut rangka diambil rangka bawa yang dianggap paling kritis menerima beban, dengan $\mathrm{F}=632,304 \mathrm{~kg}, \mathrm{n}=3, \mathrm{~d}=14 \mathrm{~mm}$. Tegangan geser yang 
terjadi adalah $1,369 \mathrm{~kg} / \mathrm{mm}^{2}$. Perhitungan baut untuk mutipleks dengan $\mathrm{F}=25 \mathrm{~kg}, \mathrm{n}$ $=6, \mathrm{~d}=10 \mathrm{~mm}$. Tegangan gerser yang terjadi adalah $0,106 \mathrm{~kg} / \mathrm{mm}^{2}$. Perhitungan baut untuk point dengan $\mathrm{F}=100 \mathrm{~kg}, \mathrm{n}=1, \mathrm{~d}=6 \mathrm{~mm}$. Tegangan geser yang terjadi adalah $3.538 \mathrm{~kg} / \mathrm{mm}^{2}$. Dari hasil perhitungan diatas terlihat bahwa sambungan baut yang digunakan menghasilkan tegangan geser yang tidak melebihi tegangan geser izin baut sehingga dapat dikatakan sambungan baut yang digunakan adalah aman.

Seperti sambungan baut pada sambungan las ini hanya tegangan geser saja yang diperhitungkan karena tegangan tariknya sangat kecil. Berdasarkan tabel minimum las yang telah ditentukan maka dalam perancangan ini dipilih ukuran minimum las $6 \mathrm{~mm}$. Adapun elektroda yang digunakan adalah jenis AWS E 60 dengan kekuatan tarik maksimum $62.000 \mathrm{psi}\left(1 \mathrm{psi}=6,894757 \times 10^{3} \mathrm{~N} / \mathrm{mm}^{2} \sigma^{\mathrm{t}}=\right)$ jadi kekuatan tarik maksimum elektroda yaitu $427,47 \mathrm{~N} / \mathrm{mm}^{2}$. Jenis pengelasan yang digunakan adalah pengelasan sudut dengan tabel pengelasan $10 \mathrm{~mm}$ dan panjang 500 mm. Tegangan izin elektroda, $\sigma t=85,494 \mathrm{~N} / \mathrm{mm}^{2}$. Tegangan geser izin, $\sigma g=$ $8,5494 \mathrm{~N} / \mathrm{mm}^{2}$. Beban yang diterima yaitu $85494 \mathrm{~N} / \mathrm{mm}^{2}$. Tegangan geser yang terjadi adalah $16,046 \mathrm{~N} / \mathrm{mm}^{2}$. Dari hasil yang didapatkan terlihat bahwa tegangan geser tidak melebihi tegangan geser izin, oleh karena itu sambungan las yang digunakan aman.

Gambar merupakan alat intuk menyatakan maksud atau sebagai bahan teknik, yang mempunyai tugas meneruskan maksud dari perancang dengan tepat kepada orang yang bersangkutan. Penafsiran gambar diperlukan untuk menentukan secara obyektif, untuk itu diperlukan standar - standar sebagai tata bahasa teknik. Dalam proses pengerjaan gambar diperlukan beberapa alat dan prosedur penggambaran yang tepat, antara lain: (1) alat/bahan yang digunakan yaitu kertas ganbar sesuai dengan ukuran kebutuhan (standar), pensil gambar ukuran 0,5 dari 0,3 (seperlunya), meja gambar, penggaris/mesin gambar, mal lingkaran/jangka, sablon huruf/angka, penghapus, kertas kalkir sesuai ukuran, rotring ukuran 0,2; 0,3 dan 0,5; (b) prosedur kerja yaitu mensketsa gambar komponen Wall Climbing beserta ukuran dan bentuk/model yang sesuai dengan permintaan, selanjutnya menggambar komponen Wall Climbing sesuai aturan/kaidah yang ada, terakhir mengkalkir komponen Wall Climbing.

Persiapan bahan adalah merupakan suatu kegiatan yang harus dilakukan. Hal ini ditetapkan karena tanpa penyediaan bahan yang tepat dapat mempengaruhi proses kegiatan selanjutnya. Dalam persiapan bahan harus dilakukan/dilaksanakan sesuai dengan penggambaran teknik yang ada sebelumnya. Persiapan bahan yang dimaksud adalah sebagai berikut: (a) pemotongan bahan ST 37 uk. 7 x 70 x 6; (b) pemotongan bahan ST 37 uk. 6 × 60 x 6; (c) pemotongan bahan ST 37 Uk. 5 x 50 x 6 unutk komponen tingkat kesulitan dengan ukuran: $3,56 \mathrm{~m} ; 0,355 \mathrm{~m} ; 1,315 \mathrm{~m} ; 2,38 \mathrm{~m}$; o,675 m;0,92 m;0,82 m; $3 \mathrm{~m} ; 1,07 \mathrm{~m}$; dan 2,4 m yang masing-masing berjumlah 2 batang; (d) menyiapkan bahan UNV 8 untuk landasan Wall Climbing dengan ukuran 6 m sebanyak 2 batang dan 2,44 m sebanyak 4 batang; (e) pemotongan plat untuk plat simpul sesuai dengan bentuk dan ukuran yang diinginkan pada gambar kerja.

Kerja bangku adalah merupakan suatu istilah proses pengerjaan di bengkel mekanik yang meliputi proses pengerjaan manual diantaranya mengikir, mengebor, menggergaji dan sebagainya. Adapun bagian-bagian Wall Climbing yang dikerjakan pada kerja bangku yaitu pengeboran batang dan plat simpul untuk pemasang baut pada konstruksi Wall Climbing. Adapun prosedur kerja antara batang dan plat simpul adalah sama yaitu sebagai berikut: (1) siapkan alat dan bahan yang digunakan ; (2) 
plambing; (3) lakukan penendaan bagian yang akan di bor dengan menggunakan penetik; (4) lakukan pengeboran pada bagian yang telah ditandai dengan mata bor $\theta 10,2 \mathrm{~mm}$, dengan kecepatan $280 \mathrm{rpm}$ sampai $560 \mathrm{rpm}$ (khusus untuk plat simpul, sedang untuk batang hanya satu kali pengeboran yaitu langsung dengan mata bor $\theta 15$ $\mathrm{mm}$ ); (5) lanjutkan pengeboran dengan menggunakan mata bor $\theta 15 \mathrm{~mm}$ dengan kecepatan yang sama.

Adapun jenis pengelasan yang digunakan pada pembuatan alat ini adalah pengelasan listrik. Pengelasan listrik adalah pengelasan yang menggunakan elektroda sebagai bahan tambah/deposit cair pada sambungan benda kerja yang dilas. Untuk mencapai pengelasan yang baik pada beberapa hal yang diperhatikan sebelum melakukan melekukan pengelasan antara lain: (1) pemilihan elektroda; (2) bahan yang akan dilas; (3) jenis penyambungan las. Adapun jenis elektroda yang digunakan dalam pengelasan ini adalah jenis elektroda ASW E6013 dengan ukuran diameter 2,6 $\mathrm{mm}$ dan 3,2 $\mathrm{mm}$. Bagian-bagian dari Wall Climbing yang dikerjakan dalam pengelasan ini adalah pengelasan pada pemasangan plat simpul.

Perakitan adalah penyusunan dalam suatu bentuk yang satu sama lainnya, sehingga membentuk mekanisme kerja sesuai yang diinginkan. Adapun proses perakitan/assembling dari alat ini adalah sebagai berikut: (1) pemasangan landasan/kaki pada pondasi yang telah disediakan dengan menggunakan baut pengikat M19; (2) pemasangan landasan yang lainnya (merakit) menggunakan baut pengikat M15; (3) pemasangan rangka utama, rangka tingkat kesulitan dan rangka kepala dengan menggunakan baut pengikat M15; (4) setelah semua rangka terpasang dan dilanjutkan dengan pemasangan multipleks dengan menggunakan baut pengikat M8; (5) pastikan semua bagian telah terakit sesuai dengan posisinya; (6) lakukan pengujian terhadap benda tersebut dengan memperhatikan fungsi dari rangka tersebut.

\section{PENUTUP}

\section{Kesimpulan}

Berdasarkan penelitian ini, dapat diambil beberapa kesimpulan yaitu sebagai berikut: (a) berdasarkan penganalisaan gaya-gaya konstruksi dalam keadaan kurang aman krena tidak memenuhi syarat-syarat keseimbangan. (b) untuk menjadikan konstruksi ini lebih aman maka diperlukan landasan yang panjangnya paling kurang 8 meter agar momen dan gaya yang dihasilkan benar-benar seimbang. (c) berdasarkan perhitungan sambungan baut maupun sambungan las tegangan geser yang di hasilkan tidak melebihi tegangan geser yang diizinkan oleh baut tersebut, maka sambungan ini aman.

\section{Saran}

Apabila konstruksi kurang aman (tidak seimbang), maka dapat diambil beberapa alternatif yaitu sebagai berikut: (a) menggunakan tali sling baja; (b) menambah panjang landasan atau memilih bahan landasan yang berat jenisnya lebih besar; (c) menggunakan pondasi agar landasannya lebih aman.

\section{DAFTAR PUSTAKA}

Gunawan Rudi. 1988. Tabe Profil Konstruksi Baja. Yogyakarta. Kanisius.

Heinz Frick. 1976. Mekanika Teknik-Statistika Dan Kegunaannya 1. Yogyakarta. Kanisius. 
Oentoeng. 1999. Konstrusi Baja. Surabaya. LPPM Universitas Kristen PETRA.

PEDC. 1982. Ilmu Kekuatan Bahan. Bandung

Sato Takeshi dan Sugiarto. 1992. Menggambar Mesin. Jakarta. Praditya Paramitha.

Sularso. 1987. Dasar Perencanaan Dan Pemilihan Elemen Mesin. Jakarta. Praditya Paramitha.

Suryanto. 1995. Elemen Mesin 1. Bandung. Pusat Pengembangan Pendidikan Politeknik. 
PENA TEKNIK: Jurnal Ilmiah Ilmu-Ilmu Teknik

Volume 1, Nomor 1, Maret 2016: 63 - 72 